\title{
The Performance of Dividend ETFs: The Study of the Spillover and Leverage Effects
}

\author{
Jo-Hui Chen', Dang Trung Kien² \\ ${ }^{1}$ Department of Finance, Chung Yuan Christian University, Taiwan \\ ${ }^{2}$ College of Business, Chung Yuan Christian University, Taiwan \\ Email: johui@cycu.edu.tw, dangtrungkien.vn@gmail.com
}

How to cite this paper: Chen, J.-H. and Kien, D.T. (2019) The Performance of Dividend ETFs: The Study of the Spillover and Leverage Effects. Theoretical Economics Letters, 9, 499-510.

https://doi.org/10.4236/tel.2019.93035

Received: December 24, 2018

Accepted: March 12, 2019

Published: March 15, 2019

Copyright (c) 2019 by author(s) and Scientific Research Publishing Inc. This work is licensed under the Creative Commons Attribution International License (CC BY 4.0).

http://creativecommons.org/licenses/by/4.0/

(c) (i) Open Access

\begin{abstract}
The objective of this study is to identify the existence of spillover and leverage effects from returns and return volatilities of high yield and low yield dividend ETFs on tracing market stock indices, and vice versa. The Generalized Autoregressive Conditional Heteroscedasticity-in-Mean-Autoregressive Moving Average (GARCH-M-ARMA) and the Exponentially Generalized Autoregressive Conditional Heteroscedasticity-in Mean Autoregressive Moving Average (EGARCH-M-ARMA) are utilized by authors. The six ETFs, recognized in Top 100 ETFs of etfdb.com database, with their underlying indices are selected to represent the high and low dividend yield ETFs group. The findings show that the spillover effect in return is more happening in a group of low yield dividend ETFs, while the spillover effect on return volatilities is more dominant in a group of high yield dividend ETFs. In the case of the leverage effect, it exists in all ETFs and the stock Index, in which the negative asymmetric volatility effect more happens when comparing the positive asymmetric volatility effect.
\end{abstract}

\section{Keywords}

Dividend ETFs, Spillover Effect, Leverage Effect, GARCH, EGARCH

\section{Introduction}

The dividend-payout policy is measured as one of the critical financial decisions, and dividend payment may influence the interests of shareholders and the future growth of a firm.

Even from some school of thought, such as Miller and Modigliani [1], the dividend does not affect the value of shares based on the assumption of a perfect capital market as non-taxable dividend and issuing additional shares with the 
free cost. Proved by experimental studies of Brennan [2] and Litzenberger and Ramaswamy [3], if the dividend tax is higher than income tax from the sale of shares (capital gain), the higher dividend will reduce the value of shares.

With its primary function as a fund distribution of firms to its shareholders, dividend makes a belief that a high dividend payout should be a potential idea when investing in the stock market. According to Graham and Dodd [4], if investors prefer dividends, an increase in the dividend may enhance the shares value. Besides, high dividend payments may reduce the volatility of future cash flows; a high payout ratio minimizes the cost of capital, making a higher value of shares. Experimental studies of Gordon [5] and Fisher [6] bring results that support this argument. Their findings show that the dividend has a greater impact on the share price, compared to the effect of retained earnings. Using NYSE stock return data from 1963 to 1994, the study conducted by Naranjo et al. [7] reveals that the returns are positively related to long-run taxable dividend yield.

Since early 90's, the creation of Exchange-Traded Funds (ETFs) has become one of the most outstanding financial innovations in decades. By following the performance of their benchmark indices, ETFs help investors with the less amount of capital to have a chance of investing in a basket of potential profit stocks, bonds or other types of investments. Many ETFs have been classified as dividend ETFs funds related high yields and more stability for investment portfolios growing in popularity for a while now. However, it is hard to find a specific academic study of this investment instrument. There is an interesting question if the factors lead to high yield stocks. They are the same as for the high yield ETFs. The findings of this study will be a useful application because many shareholders evaluate their target investments based on profit earning. Mainly, there are those investors who prefer the dividend payout, not only to stabilize portfolio and minimize risk, but also hedge against inflation or even accumulate a revenue stream.

The objective is to examine bilateral effects and asymmetric volatility effect of dividend ETFs on their benchmark stock index, and vice versa, utilizing ARMA-M-GARCH and ARMA-M-EGARCH model. Instead of using the standard deviation to investigate risk and return relationships in ETFs as a variety of existing literature, the coefficient of variance will be chosen in this study. The data of high yield dividend ETFs based on the list provided by etfdb.com database in which three ETFs on the top of the list will be chosen as high yield ETFs, while the other three at the bottom will be considered as the group of low yield dividend ETFs. This database may secure the accuracy as well as the popularity of those ETFs in the financial market. The separation of two yield groups not only helps to compare their performance with each other but also gives a broader view of the different influence of each group on market returns and return volatilities.

In addition, the study also concerns the trend of the leverage effect happening among the dividend ETFs. This study brings significant indicators for investors, 
especially those interested in dividend investing. As of their most concerns when choosing to invest in dividend type ETFs are how much they may earn and how risky they have to face. To the best of our understanding, with no other previous research conducting about dividend ETFs, the results of spillover and the leverage effects on this financial instrument may fulfill some missing in the literature. At the same time, this finding contributes economic importance to the investors when evaluating between ETFs and stock index for their portfolios, which results in more accurate decisions to balance between risk and return of investment.

Section 2 of this study is a brief review of previous studies and some major ideas in the stock dividend yield, the ETFs and the method of GARCH-M-ARMA and EGARCH-M-ARMA also applied in this field. Section 3 represents the sample data for describing the group of high and low yield dividend ETFs, and the testing hypothesis. The empirical results will be presented in Section 4 to reveal the existences of the spillover effect of returns and return volatilities between the ETFs and stock index. The risk and leverage effects are also reviewed at the end. Section 5 is the conclusion.

\section{Literature Review}

The discussion on whether the positive relationship between stock returns and dividend yields has been evidenced in empirical studies. Litzenberger and Ramaswamy [3] revealed that there was a positive and non-linear relationship between expected dividends and stock returns. Intuitively, high dividends are desirable for stockholders as an immediate profit, but low payout ratios can be good too. According to Zvi, Alex and Alan [8], low payouts can signal the company growing rapidly, while capital turnover associated with the potential investment project brings high total returns. Other studies by Cochrane [9] revealed that the key element of variation for the dividend yield connected with the market portfolio was return predictability. Likewise, the study of Maio and Clara [10] implied the estimates from a first-order vector autoregression (VAR) shows that future dividend growth can be predicted by the dividend-to-price ratio of small stocks, while it is a signal about return predictability, especially with larger stocks at longer horizons.

Since the first introduction of ETF in the form of Standard and Poor's Depository Receipts (SPDRs) in the US market in 1993, today ETFs have become one of the popular investment vehicles in the financial markets. According to Anderson et al. [11], ETFs were index funds on behalf of a basket of stocks that traded on a stock exchange throughout the day. Distinct from mutual funds, ETFs can be sold short and purchase on the margin as the share. Patro [12] examined the announcement effect of international ETFs on the returns of the tracing market index returns and closed-end fund premiums. The results showed that a positive reaction existed in the market indexes while the premium for closed-end funds had a decline effect. Reviewed by Harper et al. [13], ETFs 
provided a high risk-adjusted returns as part of an internationally diversified portfolio comparing to closed-end funds.

The effects of ETFs have been strongly backed by prior research in which mentioning about pricing efficiency of ETFs and underlying stock index changes in the volatility of security are examined [14] [15]. Moreover, Gao [16] highlighted the advantage of ETFs which were "diversification, convenience, simplicity, cost-effectiveness, transparency, flexibility, tax-efficiency, and variety". Deville [17] pointed out that the advent of ETFs not only enhanced the liquidity of the individual stock, but also increased the efficiency of an index for derivatives markets. Compared to other types of funds, the benefits of ETFs are more attractive to study in this field. Among them, the study of the spillover and leverage effects on ETFs returns and return volatilities present potential. Lin and Chiang [15] applied the GARCH model and found that asymmetric volatility in Taiwan's Top 50 Tracker Fund was contingent on increased volatility of financial and electronic component stocks. While using GARCH-ARMA and EGARCH-ARMA models to check spillover effects of ETFs, Chen and Huang [18] and Singh [19] [20] examined the spillover and the leverage effects on returns and return volatilities of stock indexes and ETFs for both emerging markets and developed countries.

Furthermore, Chen [21] focused on the ethical and non-ethical ETFs against their underlying stock indices. Chen and Diaz [22] studied Faith-based ETFs using GARCH-M-ARMA and EGARCH-M-ARMA. They all show a bilateral connection between ETFs and the benchmark indexes. Another study is applying GARCH family model by Huang et al. [23]. They used MSCI world index to compare their forecasting performance on value-at-risk ( $\mathrm{VaR})$, and the findings suggested that GARCH-in-mean model outperformed other models.

The dividend ETFs is one of the popular financial instruments. However, among the variety of research conducted about ETFs, of no earlier study has examined for the influence of high and low yield dividend ETFs. Thus, this study aims to fill this gap by considering the high yield ETFs performance when compared to the low yield ETFs. Following the method applied by Chen [21] and Chen and Diaz [22], this work will study the spillover and leverage effects to learn wherever the effects that ETFs may bring their market index, vice versa.

\section{Data and Methodology}

This study uses daily closing prices of ETFs and their corresponding stock index from the Yahoo Finance website. A cross-check of the data provided by investing.com database eliminates missing or unclear data. The list of top 100 dividend yields ETFs analyzed by etfdb.com was used as the reference to choose the testing sample. After removing the insufficient data, 3 ETFs from Top 100 ETFs were selected as the representative for high yield group, while the other three at the bottom of the list 100 were included as low yield group for comparison. The study period based on various ETF inception dates until December 2017, with 
no data earlier than January 1st of 2012. In total, 22,800 daily data of ETFs and stock index was used as the dataset for this study.

The logarithm of daily closing prices (return) is used to compute the return of both the stock index and the ETF. In detail, the difference between the logarithm of the price at time $t-1$ for ETFs and the difference between the logarithm of the index $(I)$ at time $t$ and time $t-1$ for the stock index is calculated with the equations below.

$$
\begin{aligned}
& R_{i, t}^{m}=\ln \left(\frac{I_{t}}{I_{t-1}}\right) * 100, \\
& R_{i, t}^{e}=\ln \left(\frac{P_{t}}{P_{t-1}}\right) * 100,
\end{aligned}
$$

where, $R^{m}$ and $R^{e}$ represent stock index returns and the ETFs returns at time $t$, respectively. $I$ and $P$ are stock index and ETF closing price, respectively.

Followed by the study of Chen and Huang [18] and Chen [21], the EGARCH-M-ARMA model is applied in the study of the spillover effect. The interdependence between a stock index and ETF returns is affected by market shocks.

The spillover effects for returns and return volatilities are illustrated as follows:

$$
\begin{aligned}
& R_{i, t}^{e}=\alpha_{o}+\sum_{i=1}^{g} \alpha_{i} R_{i, t-i}^{e}+w R_{i, t-1}^{m}+\varepsilon_{i, t}^{e}+\sum_{i=1}^{s} \theta_{i} \varepsilon_{i, t-i}^{e}+z h_{i, t}^{e} \text {, } \\
& h_{i, t}^{e}=a_{o}+\sum_{i=1}^{p} \alpha_{i} \varepsilon_{i, t-i}^{e^{2}}+\sum_{i=1}^{p} \Psi_{i} h_{i, t-i}^{e} \text {, for GARCH, } \\
& R_{i, t}^{m}=\beta_{o}+\sum_{i=1}^{g} \alpha_{i} R_{i, t-i}^{e}+d R_{i, t-1}^{e}+\varepsilon_{i, t}^{m}+\sum_{i=1}^{s} \gamma_{i} \gamma_{i, t-i}^{m}+k h_{i, t}^{m}, \\
& h_{i, t}^{m}=b_{o}+\sum_{i=1}^{q} b_{i} \varepsilon_{i, t-i}^{m^{2}}+\sum_{i=1}^{q} \zeta_{i} h_{i, t-i}^{m} \text {, for GARCH, } \\
& R_{i, t}^{e}=\alpha_{o}+\sum_{i=1}^{g} \alpha_{i} R_{i, t-i}^{e}+w R_{i, t-1}^{m}+\varepsilon_{i, t}^{e}+\sum_{i=1}^{s} \theta_{i} \varepsilon_{i, t-i}^{e}+z h_{i, t}^{e} \text {, } \\
& \log \left(h_{i, t}^{e^{2}}\right)=a_{o}+\sum_{i=1}^{q}\left(a_{i}\left|\frac{\varepsilon_{i, t-i}^{e}}{h_{i, t-i}^{e}}\right|+\delta_{i} \frac{\varepsilon_{i, t-i}^{e}}{h_{i, t-i}^{e}}\right) \text {, for EGARCH, } \\
& +\sum_{i=1}^{p} \Psi_{i} \log \left(h_{i, t-i}^{e^{2}}\right)+v \varepsilon_{i, t-i}^{m^{2}} \\
& \varepsilon_{i, t}^{e} \mid \Psi_{t-1} \sim N\left(0, h_{(i, t)}^{e}\right) \\
& R_{i, t}^{m}=\beta_{o}+\sum_{i=1}^{g} \alpha_{i} R_{i, t-i}^{e}+d R_{i, t-1}^{e}+\varepsilon_{i, t}^{m}+\sum_{i=1}^{s} \gamma_{i} \gamma_{i, t-i}^{m}+k h_{i, t}^{m}, \\
& \log \left(h_{i, t}^{e^{2}}\right)=b_{o}+\sum_{i=1}^{q}\left(b_{i}\left|\frac{\varepsilon_{i, t-i}^{m}}{h_{i, t-i}^{m}}\right|+\delta_{i} \frac{\varepsilon_{i, t-i}^{m}}{h_{i, t-i}^{m}}\right) \text {, for EGARCH, } \\
& +\sum_{i=1}^{p} \zeta_{i} \log \left(h_{i, t-i}^{m^{2}}\right)+l \varepsilon_{i, t-i}^{e^{2}} \\
& \varepsilon_{i, t}^{m} \mid \Psi_{t-1} \sim N\left(0, h_{i, t}^{m}\right),
\end{aligned}
$$

where $\boldsymbol{w}$ and $\boldsymbol{d}$ denote the coefficients for the lagged stock index returns and the dividend ETFs return, respectively. $\boldsymbol{v}$ and $\boldsymbol{l}$ stand for the stock index and ETFs' 
return volatilities. $\mathcal{E}$ represents the residual, $\mathrm{h}$ is the conditional variances, and $\theta$, $\gamma$ stand for the unknown parameters. Previous studies by Chou [24] and French, Schwert, and Stambaugh [25] used the standard deviation to represent the risk, and the relationship between risk and return is denoted by $\mathrm{z}$ and $\mathrm{k}$ coefficients in the variance in this study.

Based on the null hypothesis of:

- There is no spillover effects of returns: $w=0 ; d=0$,

- There is no spillover effects of returns volatilities: $v=0 ; 1=0$,

against the alternative hypotheses of there is an existence of spillover effect between the returns (volatility) of ETF and its corresponding stock index.

In addition, from the comparison between GARCH's family model with the leverage effect in the study of Rodriguez and Ruiz [26], they concluded that EGARCH specification is the most flexible. Also, the reviews of Chen and Diaz [22], Chou [24], Singh [19] [20] and French, Schwert, and Stambaugh [25] considered the leverage effect between the stock index and ETFs trading in the market, EGARCH-M-ARMA was also chosen to apply, where $\delta$ is leverage term in this research.

\section{Empirical Findings}

A majority of ETFs presents a slightly negative return in mean (Table 1). However, as a characteristic of the sample ETFs, the investors are concentrating on high dividend payout. And a common behavior of dividend preferred investor, and they look for a stable and acceptable income from dividend share, rather than on the different earning from trading the securities.

Table 1. Descriptive statistic.

\begin{tabular}{|c|c|c|c|c|c|c|c|c|c|c|}
\hline Group & Indices and ETFs & Type & Yield & $\begin{array}{c}\text { Period } \\
(\mathrm{mm} / \mathrm{dd} / \mathrm{yyyy})\end{array}$ & Mean & $\begin{array}{l}\text { Std. } \\
\text { Dev. }\end{array}$ & Skewness & Kurtosis & Jarque-Bera & Obs \\
\hline \multirow{6}{*}{$\begin{array}{l}\text { High } \\
\text { Yield }\end{array}$} & $\begin{array}{c}\text { Wisdom Tree Japan Hedged Real Estate } \\
\text { ETF (DXJR) }\end{array}$ & ETF & $82.54 \%$ & \multirow{2}{*}{$\begin{array}{l}04 / 28 / 2014- \\
12 / 29 / 2017\end{array}$} & -0.049 & 2.587 & -18.082 & 459.825 & $7831138^{* * *}$ & 895 \\
\hline & NYSE Composite (NYA) & Indices & & & 0.019 & 0.780 & -0.489 & 6.029 & $377.811^{\star * *}$ & 895 \\
\hline & Global X Gold Explorers ETF (GOEX) & ETF & \multirow[t]{2}{*}{$36.04 \%$} & \multirow{2}{*}{$\begin{array}{l}01 / 03 / 2012- \\
12 / 29 / 2017\end{array}$} & -0.087 & 2.895 & -0.862 & 12.410 & $5753.824^{* * \star}$ & 1509 \\
\hline & NYSE Composite (NYA) & Indices & & & 0.036 & 0.777 & -0.399 & 5.252 & $358.730^{* * *}$ & 1509 \\
\hline & Infra Cap MLP ETF (AMZA) & ETF & \multirow[t]{2}{*}{$24.44 \%$} & \multirow{2}{*}{$\begin{array}{l}10 / 02 / 2014- \\
12 / 29 / 2017\end{array}$} & -0.131 & 2.524 & -0.239 & 8.548 & $1056.996^{* * *}$ & 818 \\
\hline & NYSE Composite(NYA) & Indices & & & 0.024 & 0.796 & -0.489 & 6.004 & $340.118^{\star * *}$ & 818 \\
\hline \multirow{6}{*}{$\begin{array}{l}\text { Low } \\
\text { Yield }\end{array}$} & SPDR $^{\circledast}$ Portfolio Large Cap ETF (SPLG) & ETF & $5.50 \%$ & 01/03/2012- & 0.049 & 0.752 & -0.611 & 6.855 & $1028.518^{* * *}$ & 1509 \\
\hline & NYSE Composite (NYA) & Indices & & $12 / 29 / 2017$ & 0.036 & 0.777 & -0.399 & 5.252 & $358.730^{\star * *}$ & 1509 \\
\hline & $\begin{array}{c}\text { Power Shares Global Short Term High } \\
\text { Yield Bond Portfolio (PGHY) }\end{array}$ & ETF & $5.51 \%$ & \multirow{2}{*}{$\begin{array}{l}06 / 21 / 2013- \\
12 / 29 / 2017\end{array}$} & -0.002 & 0.370 & -0.292 & 6.397 & $564.671^{* * *}$ & 1141 \\
\hline & NYSE Composite (NYA) & Indices & \multirow{3}{*}{$5.53 \%$} & & 0.031 & 0.754 & -0.490 & 5.917 & $450.279^{* * *}$ & 1141 \\
\hline & $\begin{array}{c}\text { iShares } 0 \text { - } 5 \text { Year High Yield Corporate } \\
\text { Bond ETF (SHYG) }\end{array}$ & ETF & & \multirow{2}{*}{$\begin{array}{l}10 / 17 / 2013- \\
12 / 29 / 2017\end{array}$} & -0.005 & 0.272 & -0.184 & 7.033 & $723.608^{* * *}$ & 1059 \\
\hline & NYSE Composite (NYA) & Indices & & & 0.025 & 0.759 & -0.521 & 6.033 & $453.924^{* * *}$ & 1059 \\
\hline
\end{tabular}

Note: ${ }^{*}{ }^{* *}$ and ${ }^{* * *}$ denote significance at $\mathrm{a}=10 \%, 5 \%$ and $1 \%$, respectively.Authors' calculation. 
It can be observed that the high yield dividend ETFs group has more volatility than the low yield dividend group. In particular, GOEX presented the highest volatility (2.895). Based on the findings of Docking and Koch [27], dividend change announcements cause a larger variation in the stock price. While Black and Scholes [28] revealed that the stock price might change temporarily related to the change in the dividend, the results indicated that the change signals something about the likelihood for future earnings. Due to the high dividend announcement, it can be explained by the high volatility in this group. In addition, all the ETFs from the group of low yield dividend also perform lower volatility than its corresponding market stock index. Further, most of the samples are negatively skewed and are of leptokurtic distribution. The assumption of the normal distribution cannot be accepted because all Jarque-Bera statistics are significant.

In Table 2, it indicates that all the Augmented Dickey-Fuller (ADF) test is significant, which mean the testing time series data for ETFs returns and stock index returns are all stationary. This paper used the minimum value of the Akaike Information Criterion (AIC) to choose the best orders of the ARMA, GARCH and EGARCH models. A null hypothesis of no serial correlation has been tested by the Breusch-Godfrey LM test. The results indicate that there is no serial correlation due the fact that the null hypotheses cannot be rejected.

To test for the ARCH effect, the Autoregressive Conditional Heteroscedasticity Lagrange Multiplier (ARCH-LM) was chosen. High yield ETF, i.e. DXJR, presents the insignificant result. Most of other ETFs and stock index are significant in ARCH-LM test. It means that the null of no ARCH effect for the model rejected. The ARCH-LM can be re-conducted to examine the capability to eliminate ARCH

Table 2. Unit Root, LM, ARCH-LM, and EGARCH tests for Stock Index and ETFs return.

\begin{tabular}{|c|c|c|c|c|c|c|c|c|c|c|c|c|c|}
\hline Group & $\begin{array}{c}\text { Indices and } \\
\text { ETFs }\end{array}$ & Type & $\mathrm{ADF}$ & ARMA & AIC & LM & $\begin{array}{l}\text { ARCH } \\
\text { LM }\end{array}$ & GARCH & AIC & $\begin{array}{c}\text { ARCH } \\
\text { LM }\end{array}$ & EGARCH & AIC & $\begin{array}{c}\text { ARCH } \\
\text { LM }\end{array}$ \\
\hline \multirow{6}{*}{$\begin{array}{l}\text { High } \\
\text { Yield }\end{array}$} & DXJR & ETF & $-30.189^{* * *}$ & $(1,1)$ & 4.740 & 0.119 & 0.006 & $(0,1)$ & 4.512 & 0.007 & $(1,2)$ & 2.361 & 2.361 \\
\hline & NYSE & Indices & $-30.062^{* * *}$ & $(3,3)$ & 2.343 & 0.363 & $99.926^{\star * *}$ & $(3,2)$ & 2.084 & 1.102 & $(3,1)$ & 2.030 & 0.505 \\
\hline & GOEX & ETF & $-39.216^{\star * *}$ & $(2,3)$ & 4.962 & 0.000 & $5.823^{\star}$ & $(2,2)$ & 4.880 & 0.326 & $(3,3)$ & 4.857 & 2.861 \\
\hline & NYSE & Indices & $-39.054^{* * *}$ & $(3,3)$ & 2.328 & 2.048 & $118.693^{* * *}$ & $(3,3)$ & 2.151 & 0.165 & $(3,3)$ & 2.115 & 1.328 \\
\hline & AMZA & ETF & $-24.918^{* * *}$ & $(1,2)$ & 4.666 & 1.190 & $194.358^{\star * *}$ & $(1,3)$ & 4.172 & 0.061 & $(3,1)$ & 4.125 & 0.337 \\
\hline & NYSE & Indices & $-28.400^{* * *}$ & $(3,1)$ & 2.384 & 1.565 & $89.362^{* * *}$ & $(3,3)$ & 2.115 & 2.177 & $(3,2)$ & 2.062 & $8.230^{* *}$ \\
\hline \multirow{6}{*}{$\begin{array}{l}\text { Low } \\
\text { Yield }\end{array}$} & SPLG & ETF & $-38.247^{\star * *}$ & $(3,3)$ & 2.265 & 0.765 & $65.126^{\star * \star}$ & $(1,1)$ & 2.151 & 2.460 & $(3,2)$ & 2.082 & 1.256 \\
\hline & NYSE & Indices & $-39.054^{* * *}$ & $(3,3)$ & 2.328 & 2.048 & $118.693^{* * *}$ & $(3,3)$ & 4.061 & 0.167 & $(3,1)$ & 2.131 & 1.203 \\
\hline & PGHY & ETF & $-32.462^{* * *}$ & $(2,0)$ & 0.734 & 1.018 & $63.106^{\star * *}$ & $(1,3)$ & 0.407 & 1.463 & $(1,3)$ & 0.410 & 2.808 \\
\hline & NYSE & Indices & $-33.612^{\star * *}$ & $(1,1)$ & 2.268 & 0.662 & $118.212^{* * *}$ & $(3,3)$ & 2.063 & 1.140 & $(2,1)$ & 2.016 & 3.129 \\
\hline & SHYG & ETF & $-30.429^{\star * *}$ & $(2,2)$ & 0.223 & 2.005 & $124.039^{\star * *}$ & $(3,1)$ & -0.041 & 0.040 & $(3,3)$ & -0.108 & 0.428 \\
\hline & NYSE & Indices & $-32.693^{* * *}$ & $(3,3)$ & 2.280 & 0.545 & $113.494^{\star * *}$ & $(3,2)$ & 2.061 & 1.043 & $(3,3)$ & 2.018 & 3.158 \\
\hline
\end{tabular}

Note: ${ }^{*}{ }^{* *}$ and ${ }^{* *}$ denote significance at $\mathrm{a}=10 \%, 5 \%$ and $1 \%$, respectively. Authors' calculation. 
errors in the residuals of both GARCH-M-ARMA and EGARCH-M-ARMA models. The ARCH-LM test results suggest no autoregressive conditional heteroskedasticity for all ETFs samples, while there is an exception in the stock index sample.

Table 3 reveals the empirical results of GARCH-M-ARMA and EGARCH-M-ARMA models to estimate the spillover effects between stock index return (volatility) and ETFs' return (volatility) for groups of high and low yield dividend ETFs. Meanwhile, the existence of the leverage effect is verified by checking the significant autocorrelation through EGARCH-M-ARMA.

The spillover effect for returns has been explained by the coefficients of lagged stock index returns $(w)$ and lagged ETF returns $(d)$ which were influential in the current ETF and stock return [22]. The findings show that the spillover effect is more happening in groups of low yield dividend ETFs with a unilateral positive effect (SPLG/NYA, PGHY/NYA, SHYG/NYA), while most of the result in high yield dividend ETFs are insignificant. To explain for this phenomenon, we may consider the decision-making the process of the investor in low yield dividend ETFs. Investing in dividend ETFs somehow also means they are investing in a portfolio of stocks. When a company distributes the dividend, it also needs to retain the earning for the future project or other investment opportunities. It makes a high dividend not always a good signal for the investor as of their scare on the lower future growth of companies. Thus, the investor when investing in

Table 3. Spillover effects of returns, Spillover effects of volatilities and Leverage effect for Stock Indices and ETF return.

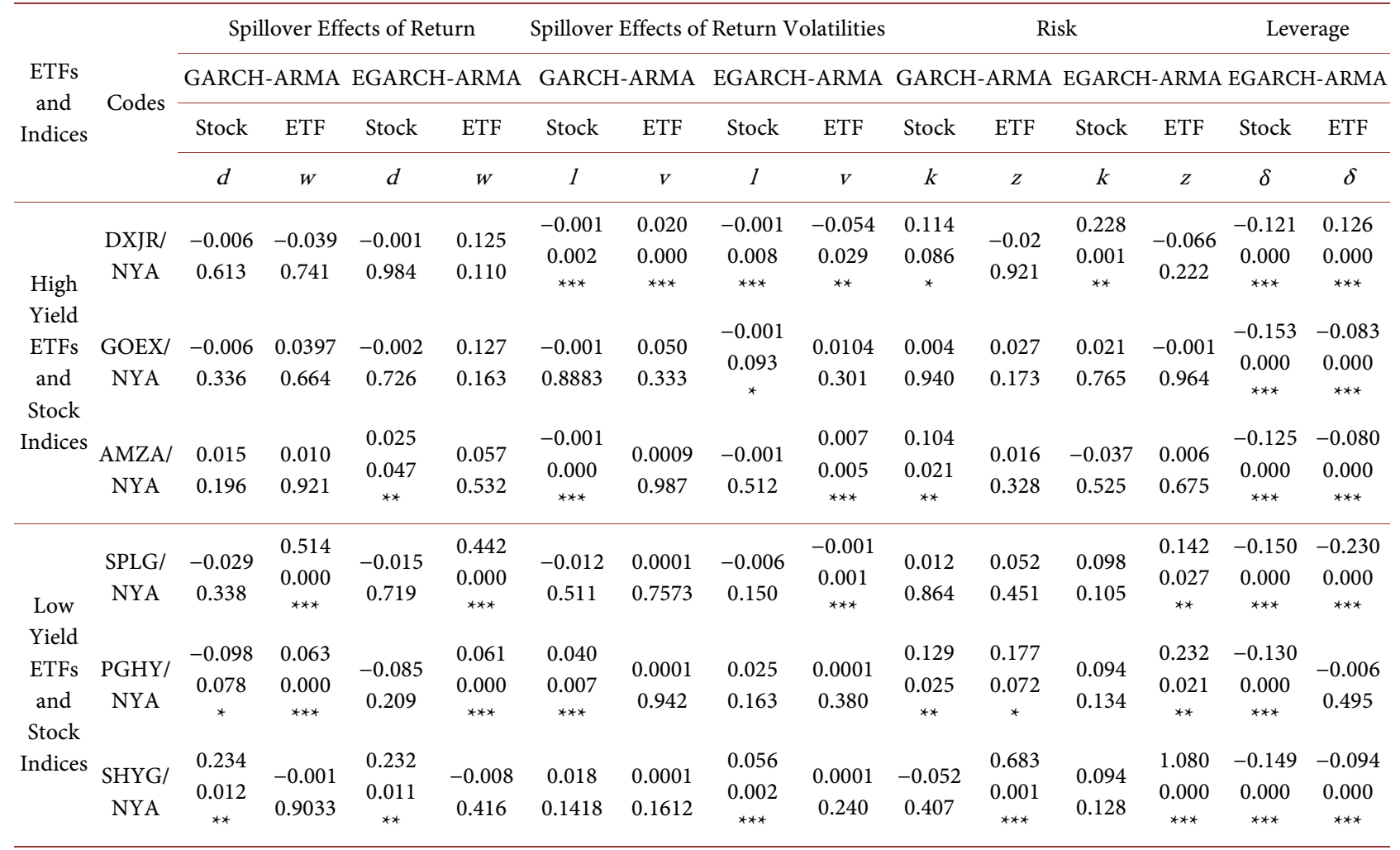

Note: ${ }^{*}{ }^{* *}$ and ${ }^{* * *}$ denote significance at $a=10 \%, 5 \%$ and $1 \%$, respectively.Authors' calculation. 
the dividend ETFs, they may not only expect for a good income currently but also maintain the stable growth of firms in the long term. This idea is especially suitable in the case of low yield dividend group.

From the side of return volatilities, the lagged of stock indices return $(I)$ and ETFs return $(v)$ have been used to test. The results showed that some spillover effects are more dominant in high yield dividend group. The result of the bilateral relationship of GARCH-M-ARMA model for DXJR/NYA is mixed by both positive and negative significant relationship. For the low yield group, the spillover effect is likely less existence. However, most of the coefficients are significantly positive, except for the slight negatively relative. The negative bilateral relationship for EGARCH-M-ARMA model such as DXJR/NYA indicates that the return volatility of the stock index may impact on the conditional variance for ETF return volatility. Meanwhile, there turn volatility of ETFs also spillover to the stock index return volatility. In reality, we may consider that the active movement on ETFs trading may create a significant influence on the market indices trade as well. This idea is essential for the investor when observing and predict stock market movement, which is identical to the finding of Chen and Huang [18] regarding the relationship between bilateral influence on volatility and trading strategy.

The empirical results of variance $k$ and $z$ stand for the relationship between return and risk. There are several coefficients significantly, which were the majorly positive sign. The results proved a widely accepted economic movement, when the risk increased, and it induced the expected return. In the case of high and low yield dividend ETFs and stock index, the raising of risk results in unilateral higher gaining for both stock index and ETFs. This finding is consistent with Chen and Diaz [22] of the Faith-based ETFs. The results of EGARCH-M-ARMA model for most of the leverage effect $(\delta$ ) are all negatively significant, which mean there is the leverage effect in all ETFs and stock indices. These results are consistent with Balaban [29] and Chen and Huang [18]. The negative asymmetric volatility effect performed strongly in most of high and low yield dividend ETFs as well as the NYA (NYSE Composite Index).

\section{Conclusions}

Among many types of research on ETFs, the missing of study on the specific field of dividend ETFs has been recognized. This study investigated the spillover and leverage effects of dividend ETFs and stock index return as well as return volatilities to fulfill the gap. Followed by the study of Chen and Huang [18], Chen [21] and Singh [19] [20], GARCH-M-ARMA and EGARCH-M-ARMA have been applied in the comparison of two groups of high yield and low yield dividend ETFs.

As for the findings, the spillover effect of return performs more frequently for low yield dividend ETFs, while the spillover effect of return volatility is dominant in the case of high yield dividend ETFs. There are several coefficients sig- 
nificant, mostly positive, in the relationship between risk and return. This result supports the idea that riskier investment goes with a higher expected return. In addition, there is the leverage effect in all ETFs and the stock Index, in which the negative asymmetric volatility effect more happens when comparing the positive asymmetric volatility effect.

The finding of this study, first, fulfills a gap in the research of dividend ETFs performance regarding the spillover effect. Secondly, it provides some evidence to the investor in predicting the market movement as well as trading decision-making, based on the connection between the ETFs and the stock market index. It is especially beneficial for dividend preferred investors. Those seeking for a stable investment channel may look at the relationship between low yield ETFs and market index as of its spillover dominant. While those preferring the price trading may consider about high yield dividend ETFs as a matter of spillover effect for volatility between ETFs and stock index more frequently in this group. However, this study remains some limitations, for example the identification of high and low dividend ETFs is still quite simple. Future researchers can improve it by applying some critical approaches to ETF's yield calculation and definition. At the same time, classifying the high yield ETFs by market, industry, geography may be potential for future investigations.

\section{Conflicts of Interest}

The authors declare no conflicts of interest regarding the publication of this paper.

\section{References}

[1] Miller, M. and Modigliani, F. (1961) Dividend Policy, Growth, and the Valuation of Shares. Journal of Business, 34, 411-433. https://doi.org/10.1086/294442

[2] Brennan, M. (1970) Tax, Market Valuation, and Corporate Financial Policy. National Tax Journal, 23, 417-427.

[3] Litzenberger, R. and Ramaswamy, K. (1982) The Effects of Dividends on Common Stock Prices Tax Effects or Information Effects? The Journal of Finance, 37, 429-443. https://doi.org/10.1111/j.1540-6261.1982.tb03565.x

[4] Graham, B. and Dodd, D.L. (1951) Security Analysis. McGraw Hills, New York.

[5] Gordon, M.J. (1959) Dividends, Earnings, and Stock Prices. The Review of Economics and Statistics, 41, 99-105. https://doi.org/10.2307/1927792

[6] Fisher, G.R. (1961) Some Factors Influencing Share Prices. Economic Journal, 71, 121-141. https://doi.org/10.2307/2228227

[7] Naranjo, A., Nimalendran, M. and Ryngaert, M. (1998) Stock Returns, Dividend Yields, and Taxes. The Journal of Finance, 53, 2029-2057. https://doi.org/10.1111/0022-1082.00082

[8] Zvi, B., Alex, K. and Alan, J.M. (2012) Essentials of Investments. McGraw-Hill/Irwin, 9.

[9] Cochrane, J. (2008) The Dog That Did Not Bark: A Defense of Return Predictability. Review of Financial Studies, 21, 1533-1575. https://doi.org/10.1093/rfs/hhm046 
[10] Maio, P. and Santa, C.P. (2015) Dividend Yields, Dividend Growth, and Return Predictability in the Cross Section of Stocks. Journal of Financial and Quantitative Analysis, 50, 33-60. https://doi.org/10.1017/S0022109015000058

[11] Anderson, S.C., Born, J.A. and Schnusenberg, O. (2010) Closed-End Funds, Exchange-Traded Funds, and Hedge Funds. Innovations in Financial Markets and Institutions. https://doi.org/10.1007/978-1-4419-0168-2

[12] Patro, D.K. (2001) Market Segmentation and International Asset Prices: Evidence from the Listing of World Equity Benchmark Shares. Journal of Financial Research, 24, 83-98. https://doi.org/10.1111/j.1475-6803.2001.tb00819.x

[13] Harper, J.T., Madura, J. and Schnusenberg, O. (2006) Performance Comparison between Exchange-Traded Funds and Closed-End Country Funds. Journal of International Financial Market Institutions and Money, 16, 104-122. https://doi.org/10.1016/j.intfin.2004.12.006

[14] Ackert, L.F. and Tian, Y.S. (2000) Arbitrage and Valuation in the Market for Standard and Poor's Depositary Receipts. Financial Management, 29, 71-88. https://doi.org/10.2307/3666230

[15] Lin, C. and Chiang, M. (2005) Volatility Effect of ETFs on the Constituents of the Underlying Taiwan 50 Index. Applied Financial Economics, 15, 1315-1322. https://doi.org/10.1080/09603100500389630

[16] Gao, S. (2001) ETFs, the New Generation of Investment Funds. ETFs and Indexing, 1, 101-105.

[17] Deville, L. (2008) Exchange Traded Funds: History, Trading and Research. Handbook of Financial Engineering, 18, 1-37. https://doi.org/10.1007/978-0-387-76682-9_4

[18] Chen, J. and Huang, C. (2010) An Analysis of the Spillover Effects of Exchange Traded Funds. Applied Economics, 42, 1155-1168. https://doi.org/10.1080/00036840701721182

[19] Singh, A.P. (2016) Do Technology Spillovers Accelerate Performance of Firms? Unravelling a Puzzle from Indian Manufacturing Industry. Economics and Applied Informatics, 3, 108-120.

[20] Singh, A.P. (2017) Does FDI Promote Productivity? A Deep Dive. Indian Journal of Industrial Relations, 52, 443-455.

[21] Chen, J. (2011) The Spillover and Leverage Effects of Ethical Exchange Traded Fund. Applied Economics Letters, 18, 983-987. https://doi.org/10.1080/13504851.2010.520663

[22] Chen, J. and Diaz, J.F. (2012) Spillover and Leverage Effects of Faith-Based Exchange Traded Funds. Journal of Business and Policy Research, 7, 1-12.

[23] Huang, H.C., Su, Y.C. and Tsui, J.T. (2015) Asymmetric GARCH Value-at-Risk over MSCI in Financial Crisis. International Journal of Economics and Financial Issues, 5, 390-398.

[24] Chou, R.Y. (1987) Volatility Persistence and Stock Valuations: Some Empirical Evidence Using GARCH. Journal of Applied Econometrics, 3, 279-294. https://doi.org/10.1002/jae.3950030404

[25] French, K.R., Schwert, G.W. and Stambaugh, R.F. (1987) Expected Stock Returns and Volatilities. Journal of Financial Economics, 19, 3-29. https://doi.org/10.1016/0304-405X(87)90026-2

[26] Rodriguez, M.J. and Ruiz, E. (2009) GARCH Models with Leverage Effect: Differences and Similarities. Working Paper 09-03, Departamento de Estadística, Univer- 
sidad Carlos III de Madrid.

[27] Docking, D.S. and Koch, P.D. (2005) Sensitivity of Investor Reaction to Market Direction and Volatility: Dividend Change Announcements. Journal of Finance Research, 28, 21-40. https://doi.org/10.1111/j.1475-6803.2005.00112.x

[28] Black, F. and Scholes, M. (1974) The Effects of Dividend Yield and Dividend Policy on Common Stock Prices and Returns. Journal of Financial Economics, 1, 1-22. https://doi.org/10.1016/0304-405X(74)90006-3

[29] Balaban, E.A. (2005) Stock Returns and Volatility: Empirical Evidence from Fourteen Countries. Applied Economics Letter, 10, 603-611.

https://doi.org/10.1080/13504850500120607 